\title{
The awareness of judicial accounting techniques towards the expectations of the external auditor in detecting fraud and its impact on the performance
}

\author{
Azza Helmy Mahmoud Shalaby ${ }^{a *}$ and Ahmad Abdulkareem Mohammad Al-Harkan ${ }^{\mathrm{b}}$
}

${ }^{a}$ Assistant Professor, Qassim University. College Of Business Administration in RASS, Accounting Section, Saudi Arabia ${ }^{b}$ Associate Professor, Qassim University. College Of Business Administration in RASS, Accounting Section, Saudi Arabia

\section{H R O N I C L E}

Article history:

Received June 12, 2021

Received in revised format

September 232021

Accepted October 122021

Available online

October 122021

Keywords:

Financial fraud

External auditor

Judicial accounting techniques

Judicial accountant

\section{A B S T R A C T}

Judicial accounting outputs are reports that guide judges in conflicting parties over financial litigation, supporting judicial cases, and settling and resolving disputes. As a discipline, judicial accounting applies the science and knowledge of accounting, such as finance, taxation and auditing in the form in which the judicial accountant can provide his expert opinion, through the availability of a set of techniques in the field of fraud investigation and support of lawsuits, to investigate the allegations alleged by the relevant parties, especially those allegations related to the existence of fraud, as the objective of the judicial accountant will depend on the purpose of his assignment, including investigating the presence of fraud. The external auditor's reliance on the sampling method when checking financial disclosure and his lack of responsibility for detecting fraud highlights the importance of judicial accounting in detecting fraud by employing a set of techniques, to assist him in detecting fraud. The achievement of its objectives by the judicial accountant also requires set of characteristics such as education, training, diverse experience in the field of accounting, auditing and law, oral and written communication skills, and the ability to work in a team environment. Judicial accounting is based on a range of techniques, for instance, including Benford's law, computer-based audit tools, data mining and analysis to show the role of judicial accounting techniques in the judicial accountant's awareness of his duties towards the external auditor in detecting fraud and its impact on developing his performance.

\section{Introduction}

Judicial accounting relies on detecting actual or potential fraud, using various fraudulent methods, by checking financial statements, verifying the integrity of their numbers and free of suspicious transactions prior to presentation and disclosure to beneficiaries., another benefit of Judicial accounting is the investigation and arbitration of financial transactions, the legality of financial transfers, and the assessment of damages and amounts of compensation. Judicial accounting outputs are reports that guide judges in sentencing parties in financial cases. To address the major challenges that may hinder the external auditor from providing useful information for decision-making at various levels, The external checker's task is concentrating an opinion on the compatibility of the company's financial reporting process with international or local accounting standards. Therefore, the detection of fraud in the records of the Economic Unit is not within its competence and the perpetrators of fraud are therefore safe from it. And that the responsibility for detecting fraud lies with the company's management through the assistance of experienced and specialists using a set of techniques to identify accounts that show unusual behavior to prove the existence of fraud and to detect perpetrators or refute allegations. or report fraud (Singleton,

* Corresponding author.

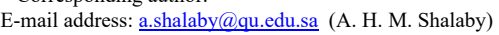


2010). Hence the importance of judicial accountability to provide and communicate information on the results of investigations to users, as well as to support lawsuits involving financial transactions through providing material financial evidence to the judiciary, as well as expressing the opinion of the expert (Bhasin, 2015). It may be difficult for users of financial reports to understand and read them, so it is necessary to recognize that there is a gap cannot be ignored between what the judicial auditor practices, and what the external auditor expects of others (Sikka et al., 1998). The effectiveness of external accounting communication depends on the parties influencing the communication process, whether from the point of view who audit the financial statements, or from the point of view of other beneficiaries (Beasley et al., 2009). One of these roles is where the external auditor is either the respondent party, such as the relationship between the external auditor and the judicial accountant, As dictated, the external auditor is dependent on him or is the influential party in the decisions of the users of the balance sheets, such as the relationship between the external auditor and the zakat examiner (Mohammed \& Dafaalla, 2014; Antunes, 2017). Hence, the need in this study was to have a set of techniques and vary in degrees of performance, which is reflected positively or negatively on the audit reports.

\section{Research methodology}

Fraud has become a scourge in the economy of many countries, as they are committing fraud by multiple internal parties such as employees and officials, as well as external, such as suppliers and customers, and that combating fraud requires working to find specialists in the field. The research problem is the extent of the impact of judicial accounting techniques on the performance of the external auditor and the judicial accountant's awareness of his duties, by applying to the practical reality of the Saudi environment. The importance of research stems from the widespread spread of fraud. The high rate of financial crimes and the occurrence of enormous economic developments in the climate of auditing and accounting, as well as the high rates of lawsuits and judicial disputes, which cost the global economy. This has increased the doubts of investors, lenders, and government agencies about the validity of the information provided by business organizations periodically. Hence, the need for experts or specialized professionals who can benefit from their expertise and skills in conducting fraud investigation and deterrence, discovering the truthfulness of the information contained in the financial statements, and expressing an opinion in the lawsuits related to financial violations and fraud in the financial statements before the courts.

The research aims to shed light on:

1. A theoretical study to show the importance of the role of judicial accounting techniques in the judicial accountant's awareness of his duties towards the external auditor in detecting fraud and its impact on developing his performance.

2. A field study to show the importance of the role of judicial accounting techniques in the judicial accountant's awareness of his duties towards the external auditor in detecting fraud and its impact on developing his performance.

\subsection{Research hypothesis}

There is no relationship between the set of judicial accounting techniques (as an independent variable) and the performance of the external auditor (as a dependent variable).

This research combines both the inductive and deductive methods by conducting a theoretical desk study of previous research in this field with the purpose of analyzing and formulating the theoretical and philosophical aspects of this research, conducting a field study based on designing a survey list and distributing it to a sample of beneficiaries of audit services, as well as a sample of external auditors and a sample of financial managers in major money companies. To measure the extent of its reflection on the examination report in Saudi Arabia, to obtain practical evidence that negates or confirms the results reached through the theoretical study, and that is through analyzing the results of the survey based on the ready-made statistical software package Minitab, SPSS to determine the extent of the validity or error of the research hypotheses. The judicial accountant relies on a variety of techniques that help him in carrying out and completing the tasks entrusted to him, especially in detecting fraud, in addition to the skills and characteristics necessary to complete his tasks and detect financial fraud practices. The judicial accountant can nominate one or more of them to carry out his duties, on the basis that each of the adopted cases requires a technique that is consistent with its nature., The following is a presentation of the most famous of these technologies:

\subsection{Data mining}

It is one of the judicial accounting techniques that helps to detect fraud practices by detecting the existence of such practices. This technique involves extracting information from data to determine previously unknown patterns and relationships. (Ijeoma, 2015). This technique relies on trying to explore a large amount of data in search of new hidden or unexpected patterns or information through programs designed for this purpose. The judicial accounting programs also cover two different groups, data mining program and financial analysis programs, where data extraction programs are designed to analyze all company database records such as invoices, debits, payments to suppliers, salaries and purchases. The financial analysis programs use the annual, quarterly and monthly financial statements and determine the ratios between different 
accounts such as the cost ratio of goods sold for sale, It can be said that the technique of data mining includes three main activities: (Mehta \& Mathur, 2017).

Exploration involves the disclosure of knowledge or patterns in data, such as correlation, trends or variables, without any prior knowledge of fraud. It is the correlation between variables, such as the occurrence of two variables, or the occurrence of one that leads to the other.

Prediction patterns: These patterns use a discovered model to estimate the results to be obtained from new values.

Analysis of the difference: The difference is extracted by defining the rule or standard and then identifying the items that deviate from the standard or rule, which are Verify anomalies, and the investigator cannot verify the legality of the fraudulent transaction. Or, for the purpose of this transaction, the best option is to find sufficient evidence of fraud from available data using specialized mathematical algorithms and data processing (Phua et al., 2010). Fraud detection research in financial accounting has been categorized according to the six data exploration applications: (Classification - Clustering - Prediction - Outlier detection - Regression - Visualization).

The data mining techniques are (Regression - Neural Networks - Bayesian Belief Network - Naïve Bayes - Nearest Neighbors (Fuzzy logic - Decision Tree - Genetic Algorithm - Expert System) (Sharma \& Panigrahi, 2013). Some researchers have attempted to apply a range of data exploration techniques, the main objective being to implement a mixed decision support system using a stacking variable approach to detecting fraudulent financial data (Kotsiantis et al., 2006). Some recent studies in financial fraud detection use two or more data exploration applications in a mixed manner or try to compare their effectiveness (Zhou et al., 2011; Perols, 2011). An analysis of the judicial accountant's ratio helps to estimate certain expenses, for example, if the unit cost sold for one of the company's goods is estimated to be $35 \%$ of the sales revenue, we can use this ratio to determine a reasonable amount of the cost of the goods sold when the company's financial records are lost under review (Metha \& Mathur, 2007).

\subsection{Data analysis}

We call the digital data ratio analysis technique, by identifying anomalies in data, which are likely to represent fraudulent activity, and since fraud involves different activities Determining the proportion of manipulation evidence, then examining the relationships between digital datasets such as the relationship between costs and units sold or sales revenue. Analysis ratios can be used to estimate some of the expenses, such as the cost of the goods sold, analysis of the gross profit ratio or other ratios that can indicate unusual elements leading to their perception as fraud (Vladu et al., 2017). The financial fraud disclosure model consists of five financial ratios - return on assets (ROA), debit accounts (A/R), sales ratio, current ratio, total asset turnover and stock turnover (Cusack \& Ahokov, 2016). Public companies suffering from these events must be disclosed and the facts explained, and financial ratios are a good way of analyzing strengths and weaknesses and turning financial information into a standard format that can be used for comparison. and industry expectations, differences in unexpected relationships that indicate mistakes, and may also refer to illegal acts or fraud (Kovalerchuk et al., 2007). Also, it is necessary to understand the public relations between certain financial reports to determine what relationships seem unusual. If cost sales increase, how should the sales respond? The answer to these questions is the fundamental financial analysis, and usually occurs between financial accounts. However, certain circumstances may lead to different outcomes (Cusack \& Ahokov, 2016).

\subsection{Benford's law}

It's a judicial accounting technique and an important law in mathematics and statistics in the modern era., This Act contributes to the examination of the quality and credibility of accounting data and the identification of anomalies in them so that further checks can be carried out. Which depends on the data showing a difference in the Benford distribution. In the Durtschi et al. (2004) study, Frank Benford noted that most of the first pages of the Logarithm were more widely used compared to the last pages of the book and reached the same conclusion that Newcomb had previously made, that individuals often looked for numbers that started with low numbers rather than those that started with large numbers. (Durtschi et al., 2004). Grammatikos noted that under the Benford Act, lower numbers are likely to appear in the first two (or three) of several higher numbers (Grammatikos \& Papanikolaou, 2015). This was confirmed by the astronomer Simon Newcombe that if the numbers are randomly collected according to this phenomenon of Benford Act or the First-Digit Law that the first pages of logarithmic tables containing small numbers are more than the next, then they become the primary reference for detection of fraud and forgery, but copycats become more familiar with this law. (Collins, 2017). If company managers work to round the net income towards the top when the net income is below psychological barriers, such as the amounts of $\$ 798,000, \$ 19.97$ million will be rounded to $\$ 800,000$ and 20 dollars respectively. The belief is that the final amounts appear to be much larger than the initial amounts, although the approximation ratio is of no relative importance. This rounding would increase the numbers that occupy the number (zero) rank second with the left hand and it reduces the numbers that occupy the number (9), her second rank, While there are smaller second-order numbers with the number (9) than expected under the Benford Act, this confirms that net income figures have been rounded (Hammood \& Corruption, 2020). In a study on quarterly net income data for a group of American companies that reported a net loss, he also indicated 
that most of the figures ending in number 9 were lower than expected., The results showed that these numbers did not match the Benford distribution (Nichols \& Wahlen, 2004). A study on the discovery of bank fraud also revealed that a bank employee accepts applicants from his friends for credit cards, then writes off the debt of balances less than $\$ 5000$, where it represents the write-off limit (Miller et al., 2008). The Mehta study recommended also the use of the Benford Act, whereby the validity of the number lists could be tested by Comparison of fact and planned numerical iterations actual and that failure to match the results could indicate the existence of fraud in the company's financial statements, (Mehta \& Bhavani, 2017), However, a study indicate (Diekmann \& Jann, 2010). To the difficulties in using the Benford Act, and that in order to validate the Benford test, the true data must be shown to be compatible with the Benford distribution, which the Steven study showed that the mathematics test indicated that fraud was not evidence of fraud, where other unexpected alternative events existed. Miller and Nigrini (2008) and Haynes (2012) found Benford's law beneficial as an early signal of fraud and sign of bankruptcy. Although Benford Law may not accurately detect fraud, and deviations can make an analyst question its validity, it can still indicate the possibility of fraud (Mehta et al., 2017; Beneish et al., 1999) help more than one criminal fraud detection tool, although none of them could identify the exact area of fraud. The use of the Benford Law in the field of detecting financial fraud practices, as a judicial accounting technique, requires that the sample size must be large enough to show the number rank pattern, such as the accounts receivable or the sales account and others, and that the numbers are not bound by restrictions.

\subsection{Computer-based audit tools}

This technology is used to carry out some audit work that helps the judicial accountant to do his job better and at a lower cost, and its use needs to provide all the information needed for audit process in computer systems (Syan and Menon, 2012), This technique helps to test the $100 \%$ detailed audit of transactions and business account balances and other accounts to detect fraudulent practices on the basis that most of these practices are included in the records covered by the testing, as well as to identify unusual patterns in the databases of the accounting systems of economic units. Unusual patterns identify a range of tests such as paying the same list to the supplier twice on the same date on the same date. One study concluded that the increase in digital fraud had resulted in many accountants receiving IT skills and certificates for preparation as IT auditors and judicial accountants (Pan \& Seow, 2016). GAAT is the most used form of CAAT in the information technology (IT) audit profession, and this program is not based on a sample checker, but is about $100 \%$ of the data, and a number of screening methods have been implemented over the years. It has proved effective in detecting anomalies that can be indicative of fraudulent activity., For example, if the employee's loan limit is $\$ 50000$ at the bank, before borrowing it must be approved by the Commission, here the candidate chooses loans below $\$ 50000$, and can also be used on the spot to search for missing data. In another example of GAS, fraudsters sometimes write checks for themselves and then deposit the value of checks in their own bank accounts so that fraudulent checks can be identified to bank customers if possible. Also, ranking all transactions by old or still future dates can help, classification can also help identify transactions outside the normal range of statistical values, and stratified data is a GAS technique that distributes transactions across equal layers of sums. The investigator can detect some anomalies by examining these layers, if the distribution is abnormal, you can follow the investigator to see the cases if the distribution naturally refers to one or more anomalies. Thus, these anomalies in the data are the result of only two types of problems, including errors or fraud, and the use of the CATI tool can be effective in detecting fraud. Especially since these tools scan $100 \%$ of the transaction data. (Mehta et al, 2017), but the use of these GAS techniques is not a panacea, not even necessarily identifying fraud, but it draws the attention of trained IT or bank fraud. From previous studies, it is clear to the researcher that the most used criminal accounting techniques for fraud detection are concentrated in Bedford law, computer-assisted auditing tools (CAATs), data exploration, and descent analysis. Some practical cases also indicate the existence of fraud and financial fraud practices and the use of appropriate methods of judicial accounting to detect such practices and minimize their effects., that means that each of these earlier techniques has a significant role to play in detecting certain types of fraudulent activity.

2/A field study to show the importance of the role of Judicial accounting techniques in the judicial accountant's awareness of his duties towards the external auditor in detecting fraud and its impact on developing his performance,

The field study aims to investigate the common opinions in the study about the impact of applying a set of independent variables represented in Bedford's Law, Computer Assisted Auditing Tools (CAATs), Data Mining, Ratio Analysis, and affecting judicial accounting and increasing the confidence of all the concerned parties (the external auditor) as a dependent variable, All this through a field study

In light of this research problem and achieve its objectives address this research through:

\subsection{Study methodology}

This study relied on the descriptive and analytical approach, in its theoretical and field styles, where the researcher used methods of collecting primary data from the accounting literature related to the research topic. The researcher used the field method to collect data from primary sources by developing a questionnaire that serves the study's objectives, which was distributed to the study population members 


\subsection{Design and content of the poll list}

In obtaining the field study data, the researcher relied on the survey list, distributed to a selected sample of the establishments. It operates in the Kingdom of the fund's companies registered in the Saudi Stock Exchange, audit offices, and other beneficiaries such as the General Authority for Zakat and Income, academics, etc. (Concerned parties) by randomly distributing several questionnaire forms. The questionnaires used in the statistical analysis were (150) questionnaire. Most of the sample members are those with academic qualifications from university education and used closed interviews to overcome these differences, whether cultural, educational, intellectual, or other.

Table 1

Reliability coefficients for the study tool according to the internal consistency method (Cronbach Alpha)

\begin{tabular}{llccc}
\hline questions & The desired goal & $\begin{array}{c}\text { Number of } \\
\text { paragraphs }\end{array}$ & $\begin{array}{c}\text { External } \\
\text { auditor }\end{array}$ & $\begin{array}{c}\text { Other beneficiaries } \\
\text { Force search }\end{array}$ \\
& $\begin{array}{l}\text { The relationship between the set of judicial } \\
\text { accounting controls and techniques (as an } \\
\text { independent variable) and the performance of the } \\
\text { external auditor (as a dependent variable) }\end{array}$ & 5 & 80.4 & 87.6 \\
\hline
\end{tabular}

Table 1 shows that the Cronbach Alpha test was used to ensure the study tool's stability. The value of Cronbach's alpha coefficient for the study variables ranged between (80.4- 87.6), which means that there is a large degree of reliability in the answers. Therefore, the results of the study can be generalized to the study population.

Statistical methods used to analyze the data:

General Notes:

The statements are answering using Curt's pentagonal scale by selecting the respondent for one of the appropriate proportions

Next: $Y e s=3$, No $=1$ somewhat $=2$

Y: represents the dependent variable

$-\mathrm{X}_{1}$ to $\mathrm{X}_{5}$ refer to the group of independent variants.

Table 2

The degree of relative importance in light of the change that judicial accounting controls can cause as an independent variable and its impact on the quality of the external auditor's performance as a dependent variable

\begin{tabular}{|c|c|c|c|c|c|c|c|c|c|}
\hline & \multicolumn{3}{|c|}{ Other beneficiaries } & \multicolumn{3}{|c|}{ Corporate managers } & \multicolumn{3}{|c|}{ External auditor } \\
\hline & Yes & No & somewhat & Yes & No & somewhat & Yes & No & somewhat \\
\hline $\begin{array}{l}\text { Provide and communicate accurate, timely, } \\
\text { sufficient and appropriate information to the } \\
\text { external auditor }\end{array}$ & 104 & 25 & 21 & 104 & 25 & 22 & 106 & 22 & 21 \\
\hline
\end{tabular}

It is evident from the previous Table 2 that the difference of opinion has achieved relative importance in clarifying the extent to which the quality of the external auditor's performance is affected by judicial accounting controls.

Table 3

A statement of the impact that the application of policies and procedures used for judicial accounting controls (independent variable) can have on the quality of the external auditor's performance (dependent variable):

\begin{tabular}{|c|c|c|c|c|c|c|c|c|c|}
\hline \multirow{2}{*}{ Judicial accounting controls } & \multicolumn{3}{|c|}{ Other beneficiaries } & \multicolumn{3}{|c|}{ Corporate managers } & \multicolumn{3}{|c|}{ External auditor } \\
\hline & Yes & No & somewhat & Yes & No & somewhat & Yes & No & somewhat \\
\hline Bedford's Law & 90 & 34 & 26 & 89 & 27 & 25 & 88 & 32 & 30 \\
\hline Computer Assisted Auditing Tools CAATs & 94 & 25 & 31 & 95 & 33 & 22 & 102 & 27 & 21 \\
\hline Data Mining & 101 & 24 & 25 & 88 & 37 & 25 & 99 & 23 & 28 \\
\hline Ratio Analysis & 98 & 27 & 26 & 81 & 35 & 34 & 72 & 21 & 57 \\
\hline
\end{tabular}

It is clear from the previous Table 3 the order and preference of using a set of judicial accounting techniques over the performance of the external auditor for a sample of different opinions

\section{First: using multiple regression analysis}

Y: Provide and communicate accurate, timely, sufficient and appropriate information to the external auditor 
To find out the effect of the following independent variables

$\mathbf{X}_{1}$ Bedford's Law

$\mathbf{X}_{2}$ Computer Assisted Auditing Tools CAATs.

$\mathbf{X}_{3}$ Data Mining.

$\mathbf{X}_{4}$ Ratio Analysis.

Table 4 presents the summary of the correlations among different variables of the survey.

Table 4

The correlation matrix between Independent variable and Dependant variable

\begin{tabular}{ccccccc}
\hline \multirow{2}{*}{$\mathrm{Y}$} & \multicolumn{2}{c}{ Other beneficiaries } & \multicolumn{2}{c}{ Corporate managers } & \multicolumn{2}{c}{ External auditor } \\
\cline { 2 - 7 } & $\begin{array}{c}\text { Pearson } \\
\text { Correlation }\end{array}$ & $\mathrm{p}_{-}$value & $\begin{array}{c}\text { Pearson } \\
\text { Correlation }\end{array}$ & $\mathrm{p}_{-}$value & $\begin{array}{c}\text { Pearson } \\
\text { Correlation }\end{array}$ & $\mathrm{p}_{-}$value \\
\hline $\mathrm{X} 1$ & .774 & .000 & .656 & .000 & .722 & 0.000 \\
$\mathrm{X} 2$ & .798 & .000 & .712 & .000 & .767 & 0.000 \\
$\mathrm{X} 3$ & .630 & .000 & .651 & .000 & .431 & 0.000 \\
$\mathrm{X} 4$ & .656 & .000 & .464 & .000 & .581 & 0.000 \\
\hline & ** Significant at level 1\% & \multicolumn{2}{c}{ * Significant at level 5\% }
\end{tabular}

Table 4 shows that there is a significant correlation between Emotional Intelligence and Provide and communicate accurate, timely, sufficient and appropriate information to the external auditor, increasing confidence, and achieving other beneficiaries goals, concerned parties (understudy) at level of confidence $99 \%$ for External auditor group with correlation value between .722 and .581 and significant correlation at level of confidence $99 \%$ for corporate managers group accept X1 at $95 \%$ confidence with correlation value between $.656, .464$ also, significant correlation at level of confidence $99 \%$ for x 5 and $x 6$ in other beneficiaries group with correlation value between $.774, .656$.

Table 5

The values of independent variables (Emotional Intelligence) coefficient and they have a real impact on the Reducing the state of uncertainty, reducing misunderstanding, effort and cost, increasing confidence, achieving the quality of the external auditor's performance as a dependent variable

\begin{tabular}{|c|c|c|c|c|c|c|c|c|c|c|c|}
\hline group & Variable & B & Beta & $\mathrm{t}$ & Sig. & $\mathrm{R}$ & $\begin{array}{c}\mathrm{R} \\
\text { Square }\end{array}$ & $\begin{array}{l}\text { Adjusted } \\
\text { R Square }\end{array}$ & $\begin{array}{l}\text { Durbin- } \\
\text { Watson }\end{array}$ & F Test & Sig. \\
\hline \multirow{5}{*}{ Other beneficiaries } & (Constant) & -.160 & & -1.455 & .148 & \multirow{5}{*}{.909} & \multirow{5}{*}{.827} & \multirow{5}{*}{.822} & \multirow{5}{*}{1.914} & \multirow{5}{*}{172.833} & \multirow{5}{*}{.000} \\
\hline & $\mathrm{X} 1$ & .323 & .352 & 7.529 & .000 & & & & & & \\
\hline & $\mathrm{X} 2$ & .352 & .195 & 7.112 & .000 & & & & & & \\
\hline & $\mathrm{X} 3$ & .198 & .231 & 4.699 & .000 & & & & & & \\
\hline & $\mathrm{X} 4$ & .226 & .351 & 5.510 & .000 & & & & & & \\
\hline \multirow{5}{*}{$\begin{array}{l}\text { Corporate } \\
\text { managers }\end{array}$} & (Constant) & -.220 & .230 & -1.800 & .074 & \multirow{5}{*}{.891} & \multirow{5}{*}{.794} & \multirow{5}{*}{.788} & \multirow{5}{*}{1.892} & \multirow{5}{*}{139.740} & \multirow{5}{*}{.000} \\
\hline & $\mathrm{X} 1$ & .225 & .433 & 4.939 & .000 & & & & & & \\
\hline & $\mathrm{X} 2$ & .400 & .357 & 10.018 & .000 & & & & & & \\
\hline & $\mathrm{X} 3$ & .322 & .221 & 8.394 & .000 & & & & & & \\
\hline & $\mathrm{X} 4$ & .205 & .230 & 5.384 & .000 & & & & & & \\
\hline \multirow{5}{*}{ External auditor } & (Constant) & -.244 & & -1.845 & .067 & \multirow{5}{*}{.891} & \multirow{5}{*}{.794} & \multirow{5}{*}{.788} & \multirow{5}{*}{1.883} & \multirow{5}{*}{138.884} & \multirow{5}{*}{.000} \\
\hline & $\mathrm{X} 1$ & .308 & .418 & 7.364 & .000 & & & & & & \\
\hline & $\mathrm{X} 2$ & .392 & .214 & 8.689 & .000 & & & & & & \\
\hline & $\mathrm{X} 3$ & .208 & .239 & 5.333 & .000 & & & & & & \\
\hline & $\mathrm{X} 4$ & .246 & .343 & 5.562 & .000 & & & & & & \\
\hline
\end{tabular}

From the above Table 5, it is clear that total correlation $(\mathrm{R})$ for other beneficiaries is equal to .909 which is relatively a strong value. The coefficient of determination or adjusted R-Square is also equal to $0 . .827$ which indicates that theX1, $\mathrm{x} 2$, $\mathrm{x} 3, \mathrm{x} 4$ in the model explain (.822) of any change in reducing the state of uncertainty, reducing misunderstanding, effort and cost, increasing confidence, achieving the quality of the external auditor's performance as a dependent variable, concerned parties (understudy). In addition, the regression model statistically significant at level of confidence $99 \%$ when the $\mathrm{F}$ calculated was 217.481 which is greater than $\mathrm{F}$ tabulated.

-Also, the table show that Durbin-Watson coefficient is 1.914 so there's no serial correlation between errors.

-A value of 2.0 indicates there is no autocorrelation detected in the sample. Values of 1.914 point to positive autocorrelation. 
-Table 5 shows the values of independent variables (Emotional Intelligence) coefficient and we find that the model variables statistically significant at a confidence level $99 \%$ (T calculated between $(-1.800,10.018)$ which that greater than 2.58 , then we reject the null hypothesis and accept the alternative hypothesis that the dimension of independent variables (x1, $\mathrm{x} 2$, $\mathrm{x} 3, \mathrm{X} 4)$ have real value coefficients are different from zero and they have a real impact on the Reducing the state of uncertainty, reducing misunderstanding, effort and cost, increasing confidence, and achieving the quality of the external auditor's performance as a dependent variable , concerned parties (understudy).

From the above table it is clear that total correlation ( $\mathrm{R})$ for corporate managers is equal to (.891) and this correlation is very strong. The coefficient of determination adj (R square adj) equal to (.794), and this indicates that the $\mathrm{x} 2, \mathrm{x} 4, \mathrm{x} 5$, $\mathrm{x} 6$ in the model explains .788 of any change in the reducing the state of uncertainty, reducing misunderstanding, effort and cost, increasing confidence, and achieving the quality of the external auditor's performance as a dependent variable, concerned parties (understudy). In addition, the regression model statistically significant at level of confidence $99 \%$ when the $\mathrm{F}$ calculated was 139.740 it is greater than F tabulated. Also, the table show that Durbin-Watson coefficient is 1.892 so there is no serial correlation between errors. A value of 2.0 indicates there is no autocorrelation detected in the sample. Value of 1.892 points to positive autocorrelation. Table 5 shows the values of independent variables (Emotional Intelligence) coefficient and we find that the model variables statistically significant at a confidence level $99 \%$ ( $\mathrm{T}$ calculated between $3.285,7.233$ ) which that greater than 2.58 , then we reject the null hypothesis and accept the alternative hypothesis that the dimension of independent variables $(\mathrm{x} 2, \mathrm{x} 4, \mathrm{x} 5, \mathrm{x} 6)$ have real value coefficients are different from zero and they have a real impact on the Reducing the state of uncertainty, reducing misunderstanding, effort and cost, increasing confidence, and achieving the quality of the external auditor's performance as a dependent variable, concerned parties (understudy).

From the above table it is clear that total correlation (R) for External auditor group is equal to .891, which looks strong. The coefficient of determination of adjusted R-Square is equal to .794, which indicates that $\mathrm{x} 1, \mathrm{x} 2, \mathrm{x} 3$, $\mathrm{x} 4$ in the model explain .788 of any change in the reducing the state of uncertainty, reducing misunderstanding, effort and cost, increasing confidence, achieving the quality of the external auditor's performance as a dependent variable, concerned parties (understudy). In addition, the regression model statistically significant at level of confidence $99 \%$ when the F calculated was 138.884 and it is greater than (F tabulated).

Also, the table show that Durbin-Watson coefficient is 1.883 so there is no serial correlation between errors. A value of 2.0 indicates there is no autocorrelation detected in the sample. Values of 1.25 point to positive autocorrelation. Table 5 shows the values of independent variables (Emotional Intelligence) coefficient and we find that the model variables statistically significant at a confidence level $99 \%$ (T calculated between $-1.845,8.689$ ) which is greater than 2.58 , and we reject the null hypothesis and accept the alternative hypothesis that the dimension of independent variables $(\mathrm{x} 1, \mathrm{x} 2, \mathrm{x} 3$, $\mathrm{x} 4)$ have a real impact on the reducing the state of uncertainty, reducing misunderstanding, effort and cost, increasing confidence, achieving the quality of the external auditor's performance as a dependent variable, concerned parties (understudy). From p-value there is a statistically significant difference between our group means. We can see that the significance value (i.e., $\mathrm{p}=$ $0.025)$, which is below 0.05 .

\section{Field research results}

Evidence of the imposition's morale affects the procedures and policies of tax accounting (as an independent variable) on reducing the state of uncertainty, reducing misunderstanding, effort and cost, increasing confidence, achieving the quality of the external auditor's performance as a dependent variable, concerned parties (understudy.

The correlation is positive between judicial accounting controls - and the external auditor's.

From the above it is clear that from the point of view of all parties (the external auditor, other beneficiaries (the concerned parties) and company managers) that:

-There is a strong and positive direct relationship between the combined judicial accounting techniques as an independent variable and the external auditor as a dependent variable and the quality of financial reports in providing information delivery channels to all concerned parties as a dependent variable.

\section{Conclusion, findings, and recommendations}

\subsection{Conclusion}

The researcher concluded, through the study,

-- The detection of fraud requires the use of various techniques such as Benford's law technique, computer-aided audit tools (CAATs), data mining and ratio analysis, as these techniques work to attract attention to items that show unusual or abnormal behavior, which requires the need to investigate them to discover whether they are fraudulent. Indicates fraud, error, etc.

- The profession of judicial accountants is one of the modern professions that enjoys an increasing demand for its services. 
Fraud operations involve twisted and varied methods involving deception, deception and lying that lead to harming others through the false presentation of financial statements that harm current and prospective investors who are deceived by those lists and whose decisions are irrational.

- Many fraud operations involve collusion between a number of employees and are hidden away from the auditor's observer, which requires the presence of specialized cadres such as judicial accountants to investigate it.

\subsection{Findings}

--providing sufficient and appropriate information to the external auditor has the greatest impact on the quality of the performance of other parties,

--Reducing disputes between the participating parties because of increasing the credibility of information and mutual trust, thus reducing misunderstanding, effort and cost for all parties.

-Having a strong and integrated professional performance and ensuring that the needs of the various parties are met.

-- It is now working to reduce deviations, as it represents qualitative control as it provides information to the various parties concerned

-A state of ensuring that the financial statements are free from material errors and fraud and that the overall risk level is low

-Reducing unnecessary procedures and the adequacy and appropriateness of audit procedures that are surrounded by risk and related to the examination

- restoring the confidence of investors, current and prospective lenders and various users of accounting lists and reports, and in accounting practice as a whole,

\subsection{Recommendations}

The researcher recommends some recommendations, the most important of which are the following:

-The need to develop accounting curricula in Saudi Arabia to prepare qualified judicial accountants

- Disseminate the idea of judicial accounting to Saudi companies, institutions, courts, judges and the law in order to contribute to rationalizing their decisions and to provide reasonable assurances about the absence of distortions in the financial statements and accounting reports issued

-The necessity of having legislation that defines the duties of the judicial accountant in both courts and committees

-Reconsidering the procedures of the commercial court departments and assigning a judicial accountant

-Establishing a professional association that includes judicial accountants and a requirement to belong to this association

The necessity of developing the audit curriculum, as an attempt to develop plans and programs to try to prevent its occurrence.

\section{References}

Abdalla, S. M. A. D. (2014). Factors Underlying the Gap between the Information Content of Financial Reports Saadaby Mohammed Ali Dafaalla Abdalla and Users' Needs in the Sudan (Doctoral dissertation, University of Gezira).

Antunes, A. L. F. (2017). Big data analytics applied to sensor data of engineering structures: automatic detection of outliers (Doctoral dissertation).

Beasley, M. S., Carcello, J. V., Hermanson, D. R., \& Neal, T. L. (2009). The audit committee oversight process. Contemporary Accounting Research, 26(1), 65-122.

Bhasin, M. L. (2015). Contribution of forensic accounting to corporate governance: An exploratory study of an Asian country. International Business Management, 10(4), 2016.

Beneish, M. D. (1999). A note on Wiedman's (1999) instructional case: detecting earnings manipulation. Issues in Accounting Education, 14(2), 369.

Collins, J. C. (2017). Using Excel and Benford's Law to detect fraud. Journal of Accountancy, 223(4), 44-50.

Cusack, B., \& Ahokov, T. A. (2016). Improving forensic software tool performance in detecting fraud for financial statements.

Diekmann, A., \& Jann, B. (2010). Benford's law and fraud detection: Facts and legends. German Economic Review, 11(3), 397-401.

Durtschi, C., Hillison, W., \& Pacini, C. (2004). The effective use of Benford's law to assist in detecting fraud in accounting data. Journal of forensic accounting, 5(1), 17-34.

Grammatikos, T., \& Papanikolaou, N. I. (2015). Applying Benford" s law to detect fraudulent practices in the banking industry (pp. 1-28). Working Paper.

Haynes, A. H. (2012). Detecting fraud in bankrupt municipalities using Benford's Law.

Ijeoma, N. B. (2015). Empirical analysis on the use of forensic accounting techniques in curbing creative accounting. 
Kotsiantis, S., Koumanakos, E., Tzelepis, D., \& Tampakas, V. (2006). Forecasting fraudulent financial statements using data mining. International journal of computational intelligence, 3(2), 104-110.

Kovalerchuk, B., Vityaev, E., \& Holtfreter, R. (2007). Correlation of complex evidence in forensic accounting using data mining. Journal of Forensic Accounting, 8(1), 53-88.

Mehta, A., \& Bhavani, G. (2017). Application of forensic tools to detect fraud: The case of Toshiba. Journal of Forensic and Investigative Accounting, 9(1), 692-710.

Mehta, G. S., \& Mathur, T. (2007). Preventing Financial Fraud ThroughForensic Accounting'. CHARTERED ACCOUNTANT-NEW DELHI-, 55(10), 1575.

Miller, S. J. (2008). Benford's Law and Fraud Detection, or: Why the IRS Should Care About Number Theory!.

Miller, S. J., \& Nigrini, M. (2008). Theory and applications of Benford's law to fraud detection, or: Why the IRS should care about number theory!.

Nichols, D. C., \& Wahlen, J. M. (2004). How do earnings numbers relate to stock returns? A review of classic accounting research with updated evidence. Accounting Horizons, 18(4), 263-286.

Pan, G., \& Seow, P. S. (2016). Preparing accounting graduates for digital revolution: A critical review of information technology competencies and skills development. Journal of Education for business, 91(3), 166-175.

Perols, J. (2011). Financial statement fraud detection: An analysis of statistical and machine learning algorithms. Auditing: A Journal of Practice \& Theory, 30(2), 19-50.

Phua, C., Lee, V., Smith, K., \& Gayler, R. (2010). A comprehensive survey of data mining-based fraud detection research. arXiv preprint arXiv:1009.6119.

Sharma, A., \& Panigrahi, P. K. (2013). A review of financial accounting fraud detection based on data mining techniques. arXiv preprint arXiv:1309.3944.

Sikka, P., Puxty, A., Willmott, H., \& Cooper, C. (1998). The impossibility of eliminating the expectations gap: some theory and evidence. Critical perspectives on accounting, 9(3), 299-330.

Singleton, T. W. (2010). Fraud auditing and forensic accounting (Vol. 11). John Wiley \& Sons.

Syan, C. S., \& Menon, U. (Eds.). (2012). Concurrent engineering: concepts, implementation and practice. Springer Science \& Business Media.

Vladu, A. B., Amat, O., \& Cuzdriorean, D. D. (2017). Truthfulness in accounting: How to discriminate accounting manipulators from non-manipulators. Journal of Business Ethics, 140(4), 633-648.

Zhou, W., \& Kapoor, G. (2011). Detecting evolutionary financial statement fraud. Decision Support Systems, 50(3), 570575 . 
(C) 2022 by the authors; licensee Growing Science, Canada. This is an open access article distributed under the terms and conditions of the Creative Commons Attribution (CC-BY) license (http://creativecommons.org/licenses/by/4.0/). 